\title{
A COMPARATIVE STUDY OF THE CLINICAL AND HISTOPATHOLOGICAL FEATURES OF NORMAL LABIAL MUCOSA AND REDUNDANT TISSUE IN DOUBLE LIP
}

\author{
Reda Gaber Saleh*, Elsayed Mohamed Deraz** and Altaib Abdel Razik Mohammed***
}

\begin{abstract}
Introduction: double lip is one of lip abnormalities that may be congenital or acquired. It consists of a fold of excess tissue on the mucosal side of the lip. It causes functional and aesthetic problems to affected patients
\end{abstract}

Aim of the work : The present study was performed to compare clinically and histopathologically between redundant tissue in double lip and normal labial mucosa.

Subjects and methods: Seventeen patients with congenital non syndromic double lip were selected. Redundant tissues were removed surgically together with part of adjacent normal mucosa as part of the surgical manipulation. Hematoxylin and eosin staining was done to compare both tissues microscopically. Expression of ki-67 and p53 was evaluated in both tissue by immunohistochemistry

Results: Clinically, redundant tissue appeared as thick extra fold with normal mucosal color and soft consistency analogous to normal labial mucosa. This redundant tissue was removed surgically without any complications. Histopathologically, normal labial mucosa revealed non keratinized stratified squamous epithelium and delicate underlying connective tissue. Excess tissue exhibited parakeratosis, acanthosis, elongation of rete pegs. The underlying connective tissue was fibrotic with inflammatory cell infiltration. In normal labial mucosa, ki-67 was detected only in parabasal layer of epithelium whereas it was localized in parabasal and superficial layers of epithelium in redundant tissue. No expression of p53 was detected in both normal and excess tissue. For both ki-67 and p53, the difference in expression between normal and redundant tissue was significant.

Conclusion : Redundant tissue is a benign hyperplastic tissue that require surgical removal. So surgical excision here is the treatment of choice when excess tissue causes functional and aesthetic problems. Moreover, the high proliferation of redundant tissue may necessitate the surgical excision of this tissue.

KEY WORDS : Clinical, double lip, Ki-67, P53, redundant tissue.

* Lecturer, Oral Biology, Faculty of Dentistry, Tanta University

** Assistant Professor, Oral pathology, Faculty of Dentistry, Tanta University

*** Assistant Professor, Oral and Maxillofacial Surgery, Faculty of Dentistry, South Valley University 


\section{INTRODUCTION}

Double lip (DL) is a common name of macrocheilitis $^{(1)}$. It is an unusual anomaly of oral cavity affecting generally the upper lip bilaterally, although it can also occur unilaterally in upper and lower lips. Initially, this anomaly had no gender or racial predilection $^{(2)}$. However, Palma and Taub in $2009^{(3)}$ reported that the DL more commonly affected males in the ratio of $7: 1$.

DL is a rare anomaly that may be congenital or acquired ${ }^{(4)}$, some congenital DL is associated with Asher syndromes that is associated with blepharochalesis ,thyroid goiter ${ }^{(5)}$. DL deformity can be acquired by trauma, lip sucking or ill-fitting denture $^{(6)}$

Clinically, it is characterized by an accessory fold of redundant hypertrophic tissue of labial mucous nearby the vermillion border ${ }^{(4)}$.This deformity is enough to interfere with speech and eating, also it a has sever effect on facial aesthetic ${ }^{(7)}$. Bilateral DL typically shows a Cupid's bow appearance during smiling $^{(8)}$. It is reported that DL appearance is present spontaneously at rest without tension ${ }^{(5)}$.

Ki67 expression is associated with cell proliferation and growth and is mostly used as a proliferation marker in different pathological investigations ${ }^{(9)}$. Ki67 presents during all active phases of cell cycle ( G1, S, G2 and M) and is absent in resting cell $(\mathrm{G} 0)^{(10)}$. Ki67 was used in this study to examine the proliferative characteristics of the redundant tissue in double lip.

The p53 gene has been called the "Guardian of the Genome"(11). It is referred to as a tumor suppressor gene because its normal function is to suppress the development of tumors by detecting genetic errors in G1 cells; where its transcription is increased resulting in (cell cycle arrest or apoptosis of those cells. Alterations in the p53 are among the most common genetic deviation in the chain of oral cancers ${ }^{(12,13)}$. So Mutant p53 protein loses its cancer inhibition function and thus promotes the transformation of normal cells to malignant cells $^{(14)}$. P53 was used in this study to check whether the redundant tissue in DL has a risk of malignant transformation or not

To the best of our knowledge, the clinical and histological features of the redundant tissue in DL have not been fully demonstrated. Therefore, the current study was undertaken to compare the clinical and histopathological features of both redundant tissue (excess tissue) and adjacent normal labial mucosa

\section{SUBJECTS AND METHODS}

Seventeen patients were reported to the department of oral and maxillofacial surgery faculty of oral and dental medicine South Valley University from January 2014 to January 2019. All the patients presented with congenital DL deformity and were selected after removing patients who met to the exclusion criteria of the study which included immunocompromized patients, and those of traumatic pathogenesis of double lip. The patients were diagnosed and registered as regards the age, sex and the main complain. Also, complete medical and dental history were recorded, every patient was examined generally and regionally for maxillofacial region, complete blood picture, renal and hepatic function, and prothrombin time were requested, and surgical fitness of the patients was obtained through physical consultation

The study was reviewed and approved by the Research and Ethical Committee of South Valley University. The consent for surgery and publications of scientific knowledge was obtained from the participated patients

\section{Surgery}

Surgical planning for management of DL deformity was explained to the patients. Under local anesthesia (infraorbital nerve block) to avoid distortion of the tissue mass, the redundant tissue was determined, marked and held with curved 
mosquitoes and excised along with 3-4 mm of normal labial tissue at right and left peripheries to prevent dog bite appearance, then the resulted raw wound sutured with 3, 0 resorbable sutures polyglycolic acid* primarily after slight dissection of surrounding mucosa ${ }^{(15)}$. Then antibiotic amoxicillin and clavulanic acid (augmentin) **, analgesic paracetamol (Panadol) $^{* * *}$, anti-edematous drug chymotrypsin (alphentern) ${ }^{* * * *}$ and normal saline mouth wash were prescribed for the patients. All the patients followed up for immediate postoperative periods for pain edema or wound dehiscence also the patients were followed at least one year for recurrence of DL

\section{Histopathological examination}

The excised tissues sent for histopathological comparison between the redundant tissue (group I) and normal labial mucosa (group II). The normal labial mucosa was obtained during surgical procedure by removal of 3-4 $\mathrm{mm}$ at right and left peripheries of the wound (as described before). Specimens were fixed in $10 \%$ buffered formalin for $24 \mathrm{~h}$. Then, they were washed in tap water over night and then dehydrated in ascending grades of alcohol, cleared in xylene and then embedded in low melting point $\left(56^{\circ} \mathrm{C}\right)$ paraffin. Serial sections of 5 um thickness were processed for histological $\mathrm{H} \& \mathrm{E}^{(16)}$, and for immunohistochemical labeling which performed using the avidin-biotin-complex (ABC) method ${ }^{(17)}$. The sections were processed for the Anti-Ki67 antibody (ab833) and Anti-p53 antibody [E26] (ab32389).

\section{Statistical evaluation}

After processing and staining, the slides are visualized in a L.M (Leica DM500) equipped with built-in camera (Leica ICC50 HD Camera system). Images of the H\&E and the immunostaind stained sections were analyzed using the ImageJ analysis system (ImageJ 1.48s, Wayne Rasband, National Institute of Health, USA).

Images for inflammatory cell counting in $\mathrm{H} \& \mathrm{E}$, high-density cellular areas were selected and each type of cells was counted in five high power fields at $400 \mathrm{X}$ magnification, the sections were examined by 3 blinded observers. The cells were identified morphologically and histologically ${ }^{(18)}$. Images for Anti-Ki67 antibody and Anti-P53 antibody were acquired from areas expressed the immunohistochemical DAB brown color reaction, white-balanced, and averaged to minimize noise. No further image processing was performed before image analysis. Sections were analyzed for intensity of Ki67 \& P53 expression.

All statistical analyses were performed using the (ANOVA) followed by t-test according to Mould, $1989^{(19)}$. All values were expressed in form of means and standard deviations. All statistical analyses were done on an IBM PC using the statistical software "SPSS 20" (Statistical Package for Scientific Studies) (SPSS Inc., Chicago, Illinois, USA) for windows.

Results were expressed in the form probability value ( $p$-value) that was differentiated into: nonsignificant when $\mathrm{p}$-value $>0.05$, significant when $\mathrm{p}$-value $\leq 0.05$, highly significant when $\mathrm{p}$-value $\leq$ 0.01 , very highly significant when $\mathrm{p}$-value $\leq 0.001$.

\section{Clinical Results}

The main complain about the seventeen patients was aesthetic problem, they felt abnormality on talking or laughing, where excess labial tissue appear and one complain of patient for instability of the denture, sixteen patients presented with bilateral double lip, only female patient presented with middle DL (fig.1a). Fifteen patients of bilateral

\footnotetext{
* (Vicryl $\AA^{8}$ 3.0, Ethicon Inc., Somerville, USA)

** MUP Becham

*** GLAXO

$* * * *$ AMOUN
} 
DL appeared with continuous DL (fig .1b), one of these patients showed midline constriction (fig. 2a), also one patient of lower DL was only presented (fig. 2b).

Clinically, the normal labial mucosa in all patients appeared coral pink in color, with normal coloration and consistency without any apparent pathological changes. While, the redundant tissue appeared as a thick extra fold with normal mucosal color. It was soft on palpation and fluctuant.

Patients were managed under surgical planning of DL deformity (fig .3,4\&5), the post-operative complications as pain \& edema was non-significant and managed with prescription of the drugs, all the

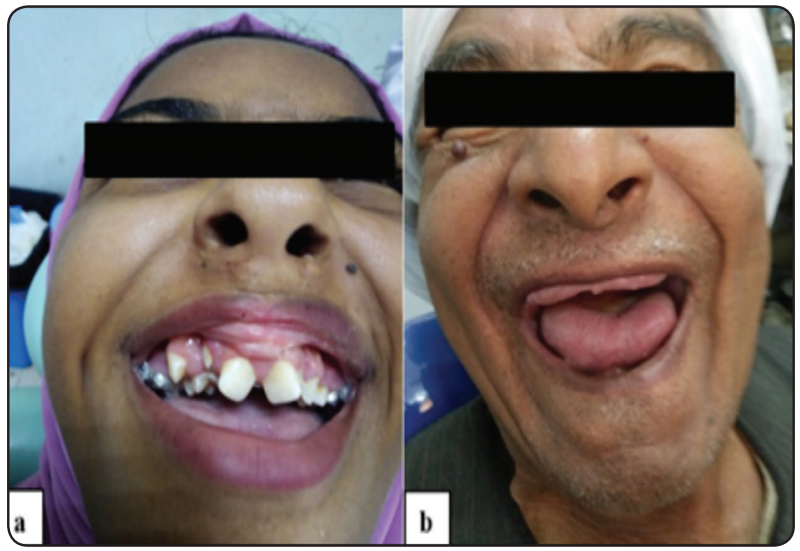

Fig. (1) (a) Female patient with upper DL with the excess tissue at the middle (middle double lip). (b) Old male patient with bilateral continuous double upper lip

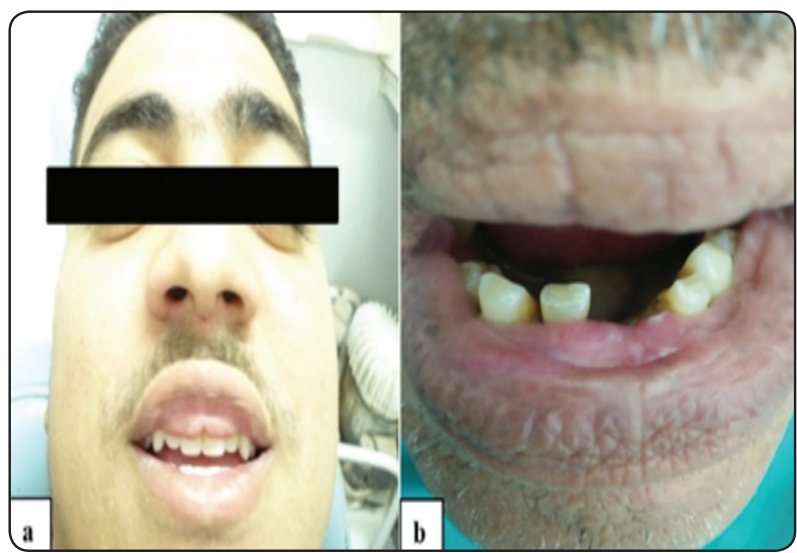

Fig. (2) (a) Male patient showing upper lip with midline constriction of the excess tissue. (b) Old male patient with double lower lip.

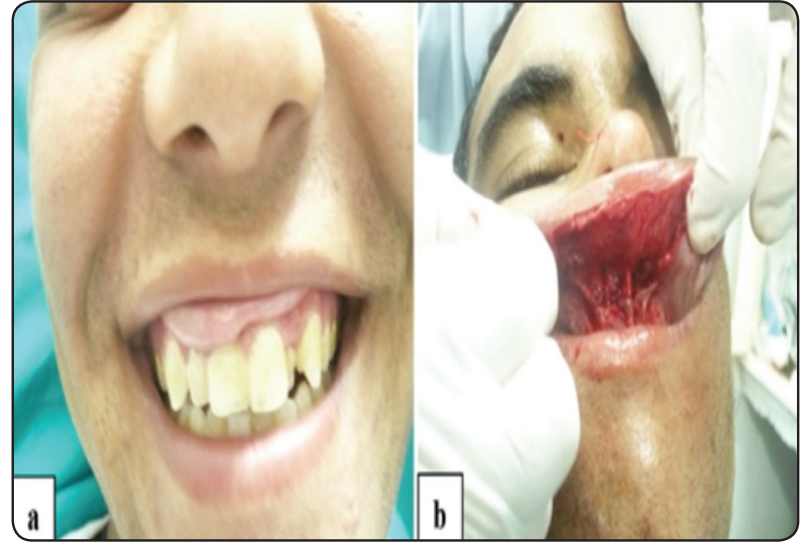

Fig. (3) (a) Male patient with double upper lip. (b) Wound after excision of excess labial tissue.

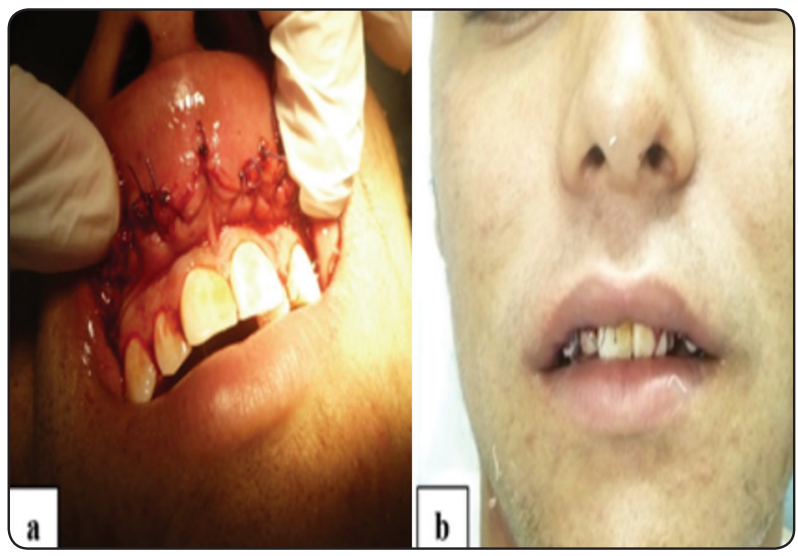

Fig. (4) (a) Sutured labial wound. (b) Immediate appearance of the upper lip after operation.

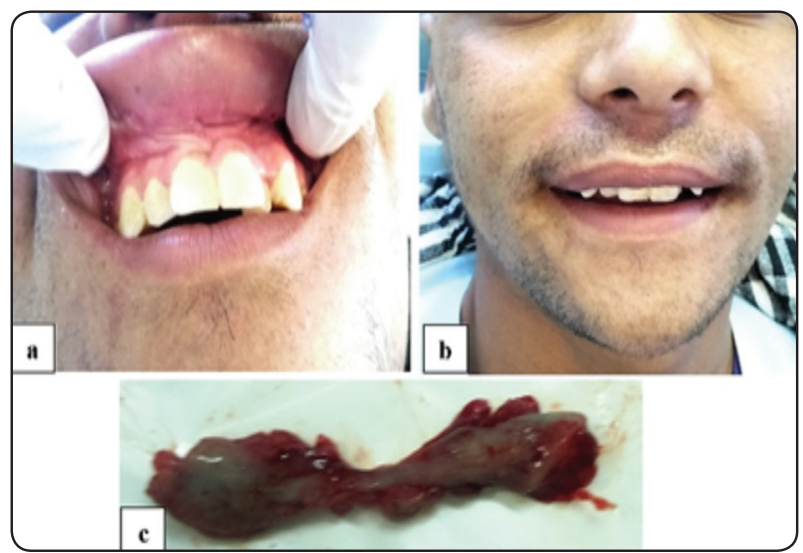

Fig. (5) (a) Eventful healing of labial wound. (b) Clinical appearance of normal upper. (c) Excised labial tissue for histopathological study 
patients were revealed excellent wound healing without dehiscence, all the patients were satisfied with the results with no recurrence through the period of follow up

\section{Histopathological results}

H\&E stained section revealed normal labial mucosa, which was covered by thick nonkeratinized stratified squamous epithelium with delicate underlying CT. While, excess redundant tissue showed parakeratosis, acanthosis, elongation and downward growth of rete ridges. The underlying CT was fibrotic and revealed an inflammatory cell infiltration. It was noticed that epithelial thickness increased gradually from normal labial mucosa to the redundant tissue at the limit of the specimen (fig.6\&7).

The salivary gland under normal labial mucosa showed normal architecture of labial minor salivary gland, mucous acini was lined by pyramidal cells with basally located flat nuclei surrounding central large lumen. Some mucous acini were capped with

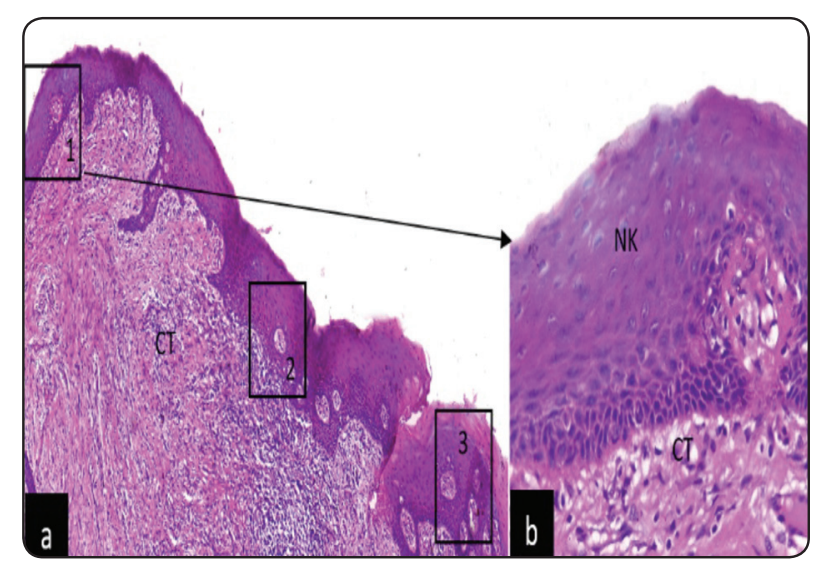

Fig. (6) Light micrograph of the excised tissues. (a) Low power of the excised tissues showing both normal labial mucosa at the frame (1), and the excess redundant tissue at the rest of the specimen with downward growth of rete ridges \& gradual increase in parakeratosis (PK). (b) Higher magnification (frame 1) of figure (a) showing thick nonkeratinized stratified squamous epithelium (NK) with delicate underlying CT. (CT) connective tissue. ( $\mathrm{H}$ and $\mathrm{E}$ original magnification, $\mathrm{A} \times 4, \mathrm{~B} \times 40$ ). serous cells. The duct system appeared normal in size and structure. These parenchymal elements were embedded in normal reticular CT stroma. But under redundant tissue the salivary gland showed normal acini, with remarkable duct dilatation and mild interstitial fibrosis (fig.8\&9).

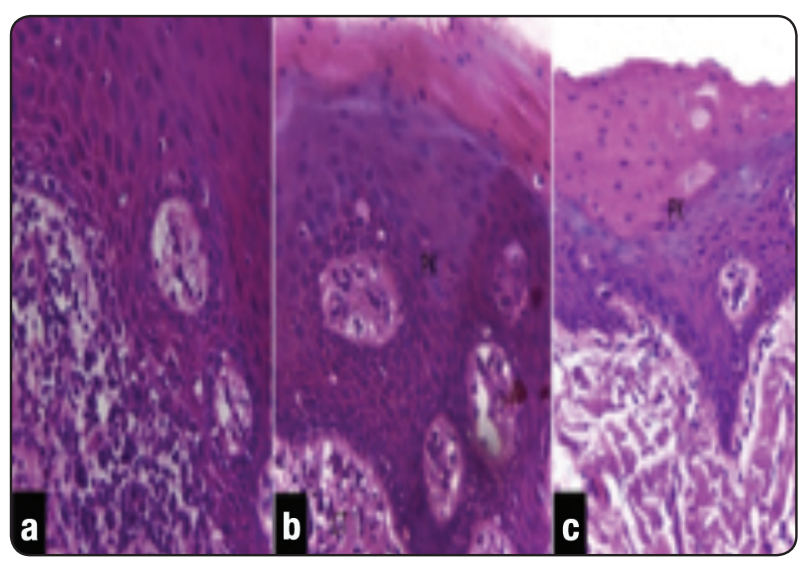

Fig. (7) Light micrograph of the excised tissues. (a) Higher magnification (frame 2) of figure (1a) showing acanthosis of epithelium with inflammatory cell infiltration of CT. (b) Higher magnification (frame 3) of figure (1a) showing PK \& acanthosis of epithelium. (c) Showing PK, acanthosis, elongation and downward growth of epithelial rete ridges with fibrotic underlying CT. (CT) connective tissue. ( $\mathrm{H}$ and $\mathrm{E}$ original magnification, A, B, C $\times 40)$.

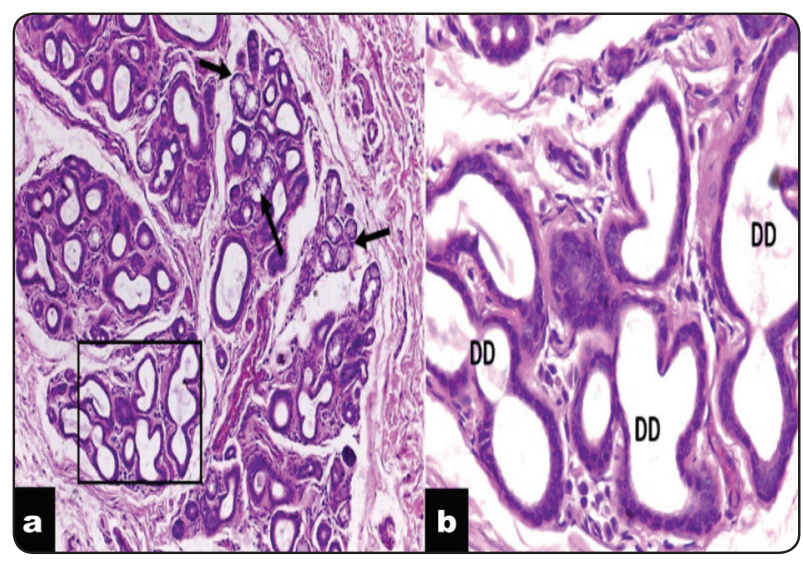

Fig. (8) Light micrograph of labial salivary gland of the excised tissues. (a) Showing lobe of labial minor salivary gland of redundant tissue with remarkable duct dilatation and mild interstitial fibrosis with some normal mucous acini (arrows). (b) Higher magnification of figure (a) showing prominent duct dilatation (DD) and mild interstitial fibrosis. ( $\mathrm{H}$ and $\mathrm{E}$ original magnification, $\mathrm{A} \times 10, \mathrm{~B} \times 40$ ). 


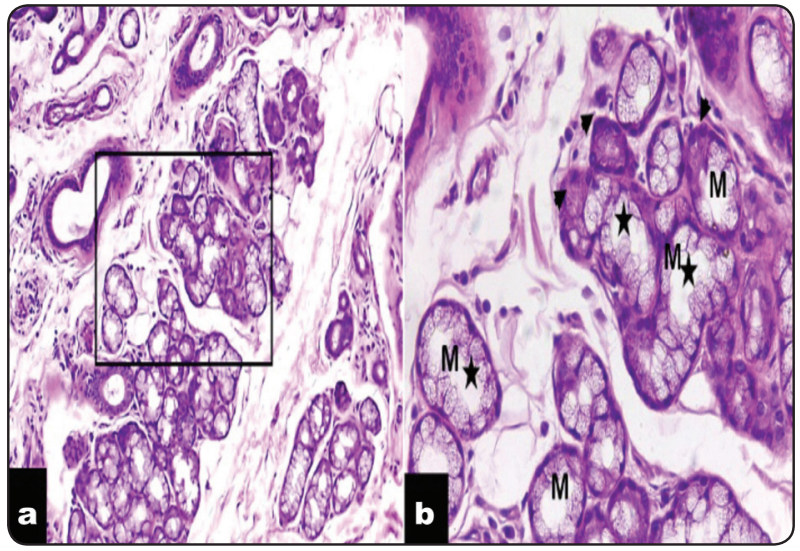

Fig. (9) Light micrograph of labial salivary gland of the excised tissues. (a) Showing lobe of labial minor salivary gland of normal labial mucosa with normal architecture of parenchymal elements and reticular CT stroma. (d) Higher magnification of figure (a) showing normal mucous acini (M) with large lumen (star). Some mucous acini capped with serous cells (arrow head). ( $\mathrm{H}$ and $\mathrm{E}$ original magnification, $\mathrm{A} \times 10, \mathrm{~B} \times 40$ ).

Immunohistochemical expression of Ki-67 was detected as a nuclear brown color in the parabasal and superficial layers of epithelium in redundant tissue. In case of normal labial mucosa, the Ki67 was detected as sporadic nuclear expression in parabasal layer of epithelium (fig.10). While, Immunohistochemical expression of p53 no detectable levels were seen in both normal labial mucosa and excess redundant tissue (fig.11)

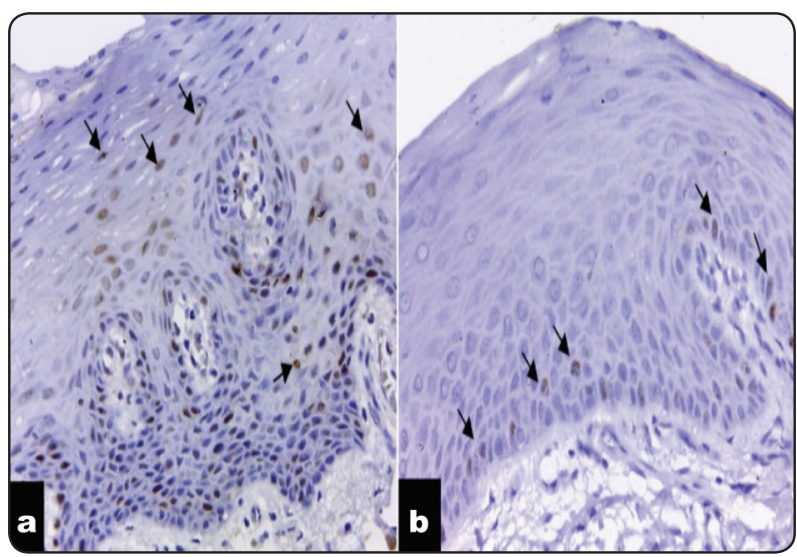

Fig. (10) Light micrograph of the excised tissues. (a) Showing nuclear Ki-67 expression in the parabasal and superficial layers (arrows) in redundant tissue. (b) Showing sporadic nuclear expression in parabasal layer of epithelium (arrows) in normal labial mucosa. (immunohistochemical technique original magnification, $\mathrm{A} \& \mathrm{~B} \times 40$ ).

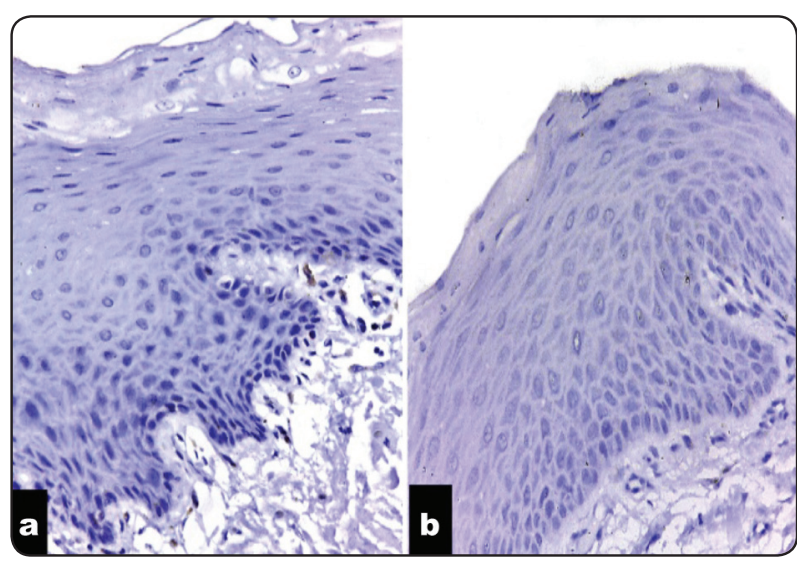

Fig. (11) Light micrograph of the excised tissues. (a) Showing no detectable epithelial expression of p53 in redundant tissue. (b) Showing no detectable epithelial expression of p53 in normal labial mucosa. (immunohistochemical technique original magnification, $A \& B \times 40)$.

\section{Statistical results}

\section{The inflammatory cell counting:}

The greatest mean value of inflammatory cell counting was recorded in group I (redundant tissue) with the least value was obtained in group II (normal labial mucosa). Analysis of variance (ANOVA) test revealed an extremely significant difference between groups ( $p$-value < 0.0001) (tab.1, fig.12 a). The t-test revealed that the difference between (group I \& group II) and (group II \& group III) was very highly statistically significant (tab.2).

TABLE (1): Inflammatory cell counting and statistical significance of the difference (ANOVA) test for groups I, II.

\begin{tabular}{|c|c|c|}
\hline & Group I & Group II \\
\hline mean & 221 & 25 \\
\hline S.D & 60.63 & 7.60 \\
\hline Max & 301 & 34 \\
\hline min & 137 & 15 \\
\hline F-value & \multicolumn{2}{|c|}{51.64} \\
\hline P-value & \multicolumn{2}{|c|}{$<0.000^{* * *}$} \\
\hline
\end{tabular}

*** extremely significant 
TABLE (2): t-test of the means of cell counting in group II and groups III.

\begin{tabular}{|l|c|c|c|}
\hline & Group I & Group II & P-value \\
\hline $\begin{array}{l}\text { inflammatory } \\
\text { cells count }\end{array}$ & $221 \pm 60.63$ & $25 \pm 7.60$ & $0.000^{* * *}$ \\
\hline
\end{tabular}

*** Very highly significant

\section{Intensity of Ki67 immunohistochemical expression}

The greatest mean intensity of Ki67 immunohistochemical expression was recorded in group I, with the least value obtained in group II. Analysis of variance (ANOVA) test revealed an extremely significant difference between groups (p-value < 0.000) (tab.3, fig.12 b).

TABLE (3): Intensity of Ki67 immunohistochemical expression and statistical significance of the difference (ANOVA) test for groups I \& II.

\begin{tabular}{|c|c|c|}
\hline & Group I & Group II \\
\hline mean & $\mathbf{1 7 7}$ & $\mathbf{5 8}$ \\
\hline S.D & $\mathbf{8 . 5 4}$ & $\mathbf{9 . 6 5}$ \\
\hline Max & $\mathbf{1 8 8}$ & $\mathbf{7 0}$ \\
\hline min & $\mathbf{1 6 9}$ & $\mathbf{4 8}$ \\
\hline F-value & \multicolumn{2}{|c|}{188.461} \\
\hline P-value & \multicolumn{2}{|c|}{$<0.000^{* * *}$} \\
\hline
\end{tabular}

*** extremely significant

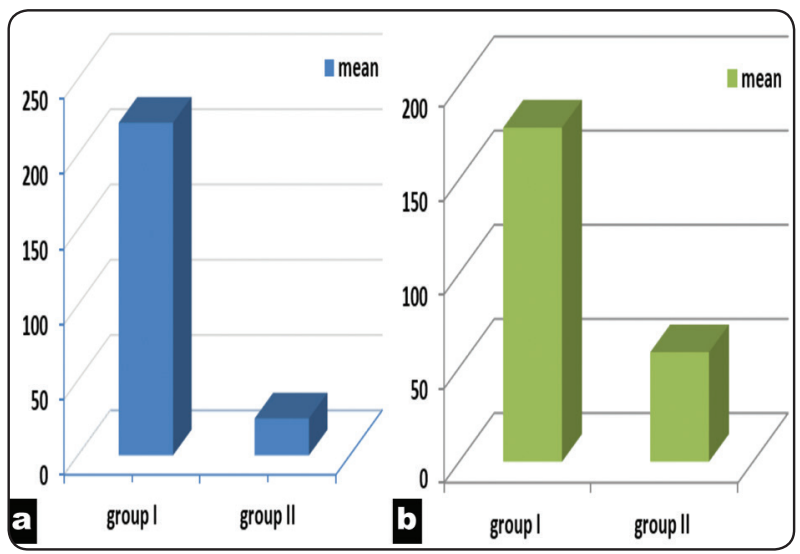

Fig. (12): Column charts representing. (a) the mean value of inflammatory cell counting for groups I, II. (b) the mean intensity of Ki67 immunohistochemical expression for groups I \& II.

\section{DISCUSSION}

DL gains a particular interest in dental field as dentists are the first health professionals to identify and diagnose this rare condition. Therefore, dentists are ideal candidates for management of these cases, thereby reducing the psychological trauma to affected patients. For correction of these cases, the treatment of choice is the surgical excision ${ }^{(20)}$.

In the current study, all cases were corrected surgically. The treatment is indicated when the condition interferes with chewing, speech or fit of dentures as well as cosmetic issue ${ }^{(15)}$.

Reported findings of DL are few. This study clinically and histopathologically compared the normal labial mucosa and excess tissue in cases of double lip. In this study seventeen cases of non-syndromic congenital DL were collected and examined both clinically and histologically to explore the nature of redundant tissue in these cases.

In the present study, the normal labial mucosa showed normal coloration and consistency without any apparent pathological changes. In contrast to normal mucosa, redundant tissue appeared as thick extra fold with normal mucosal color. It was soft on palpation and fluctuant. Kaira et al and Eski et al also demonstrated similar findings in their studies on two and five cases of DL respectively in which redundant tissue appeared as a thick fluctuant fold of mucosa with normal color ${ }^{(15,20)}$. Other chronic lip enlargement as cheilitis glandularis, fibrous hyperplasia, angioedema and salivary neoplasms should be differentiated from double lip. Macrocheilia in these cases may be inflammatory, neoplastic or have a potential for malignant transformation as stated by Wood \& Goaz, $1997^{(21)}$.

In addition, it has been suggested that DL becomes more prominent with increasing age and eruption of teeth. This finding may be explained by the repeated sucking- in of the tissue in between teeth as explained by Santos et al, $2008^{(22)}$. 
Regarding histopathological examination in the current study, normal labial mucosa exhibited thick non keratinized stratified squamous epithelium and a delicate underlying CT. These typical histological features described elsewhere as in Nanci, $2017^{(23)}$. On the other hand, excess tissue showed parakeratosis, acanthosis, elongation and downward growth of rete ridges. The underlying CT was fibrotic and revealed an inflammatory cell infiltrate. Other reports demonstrated similar findings in which the redundant tissue exhibited parakeratosis, acanthosis and elongation of rete processes ${ }^{(3,20)}$. The inflammatory response in the $\mathrm{CT}$ may be attributed to a traumatic event that occurs during mastication or due to repetitive sucking -in of the redundant tissue Hyperplasia of epithelium and fibrous overgrowth may also seen in inflammatory fibrous hyperplasia which is a reactive mesenchymal lesion, whereas congenital DL is a developmental anomaly ${ }^{(24)}$.

Ki-67 has been widely used as a proliferation marker as it is highly expressed in cycling cells but strongly down-regulated in resting G0 cells ${ }^{(25)}$. In the present study, expression of ki-67 in redundant tissue was localized to the parabasal and superficial layers of epithelium. On the other hand, sporadic expression of ki-67 was detected in only parabasal layer of epithelium in normal labial mucosa. The latter finding in normal epithelium was also observed in the results of Dwivedi et $\mathrm{al}^{(26)}$. The difference in expression between both tissues was significant. In context of these findings, a high proliferation existed in excess tissue compared to normal mucosa which may be an indication for surgical removal of redundant tissue.

It has been suggested that, p53 accumulation represents both an early event in oral carcinogenesis and a marker of field cancerization ${ }^{(27,28)}$. No detectable levels of p53 were seen in both normal mucosa and excess tissue. The absence of p53 in redundant tissue probably because the levels are too low to be detected immunohistochemically. These findings are consistent with the results of. Bongers et all ${ }^{(29)}$ in which none of the studied cases showed immunoreactivity of p53 in adjacent normal mucosa. In addition, this finding denotes that redundant tissue in DL is a benign in character and there is no potential risk of malignant transformation in this tissue similar to normal labial mucosa ${ }^{(3,20)}$. Moreover, surgical excision of this extra tissue which is the treatment of choice may be performed for aesthetic and other functional problems.

According to our results, clear differences existed between normal labial mucosa and redundant tissue in cases of double lip. In addition, surgical excision is used in most cases with appropriate results and recurrence is extremely rare.

In conclusion, treatment of congenital DL is recommended when redundant tissue causes functional problems such as interference with mastication or speech. Another important cause for surgical removal is the esthetic concerns to the affected patients. Moreover, the highly proliferative nature found in excess tissue compared to normal mucosa necessitates the surgical removal of this tissue and even follow up of treated patients.

\section{REFERENCES}

1. Lamster IBJOs, oral medicine,, pathology o. Mucosal reduction for correction of a maxillary double lip. Report of a case. 1983;55(5):457.

2. Cohen DM, Green JG, Diekmann SLJOs, oral medicine, oral pathology. Concurrent anomalies: Cheilitis glandularis and double lip: Report of a case. 1988;66(3):397-9.

3. Palma MC, Taub DIJOS, Oral Medicine, Oral Pathology, Oral Radiology,, Endodontology. Recurrent double lip: literature review and report of a case. 2009;107(3):e20-e3.

4. CHIDZONGA MM, MAHOMVA LJIjopd. Congenital double lower lip: report of a case. 2006;16(6):448-9.

5. Ali KJOs, oral medicine, oral pathology, oral radiology, endodontics. Ascher syndrome: a case report and review of the literature. 2007;103(2):e26.

6. Hanemann J, Oliveira D, Gomes MF, Sant' ana EJMooodlSEdMOydlAIdPyMB. Congenital double lip associated to hemangiomas: report of a case. 2004; 9(2):156-8, 5-6. 
7. Srivastava A, Parihar A, Soni R, Shashikanth M, Chaturvedi TJCrim. Surgical Management of a Rare Case of Congenital DoubleUpper Lip. 2011;2011.

8. Goyal S, Godhi S, Goyal SJJOHCD. Non-syndromic congenital maxillary double lip: A rare case. 2008;2(1):10-2.

9. Li LT, Jiang G, Chen Q, Zheng JNJMmr. Ki67 is a promising molecular target in the diagnosis of cancer. 2015;11(3):1566-72.

10. Scholzen T, Gerdes JJJocp. The Ki-67 protein: from the known and the unknown. 2000;182(3):311-22.

11. Lane DP. Cancer. p53, guardian of the genome. Nature 1992;358(6381):15-6.

12. Saranath D, Tandle A, Teni T, Dedhia P, Borges A, Parikh $\mathrm{D}$, et al. p53 inactivation in chewing tobacco-induced oral cancers and leukoplakias from India. 1999;35(3):242-50.

13. Muller PA, Vousden KHJCc. Mutant p53 in cancer: new functions and therapeutic opportunities. 2014;25 (3):304-17.

14. Li Y, Zhang JJOl. Expression of mutant p53 in oral squamous cell carcinoma is correlated with the effectiveness of intra-arterial chemotherapy. 2015;10(5):2883-7.

15. Eski M, Nisanci M, Aktas A, Sengezer MJBJoO, Surgery M. Congenital double lip: review of 5 cases. 2007; 45(1):68-70.

16. Jensen K. Theory and Practice of Histological Techniques, 6th Edition. Journal of Neuropathology \& Experimental Neurology. 2008;67(6):633-.

17. Saleh RG, El Tokhey A, El Guindi HJJoAS. Evaluation of hydroxyapatite nanoparticles with and without silver nanoparticles in the treatment of induced periodontitis in dogs. 2014;10(12).

18. Altaib Abdel Razik Mohammed RGSaNIS. In vivo biocompatibility of white portland cement in mandibular bone surgical defect in rabbits. Egyptian Dental Journal. 2017;63(july):445-64.

19. Mould RF. Introductory medical statistics: CRC Press; 1998.

20. Kalra N, Tyagi R, Khatri A, Poswal A, Panwar G, Garg KJIjocpd. Double Lip-An Atypical Facial Anomaly: Two Case Reports. 2018;11(5):451.

21. Wood N, Goaz PJLM. Differential diagnosis of oral and maxillofacial lesions. 4th edn, St. 1997:323-5.

22. Santos PPdA, Alves PM, Freitas VS, Souza LBdJC. Double lip surgical correction in Ascher's syndrome: Diagnosis and treatment of a rare condition. 2008;63(5):709-12.

23. Nanci A. Ten Cate's Oral Histology-E-Book: Development, Structure, and Function: Elsevier Health Sciences; 2017.

24. Neville BW, Damm DD, Allen CM, Chi AC. Oral and maxillofacial pathology: Elsevier Health Sciences; 2015.

25. Sun X, Kaufman PDJC. Ki-67: more than a proliferation marker. 2018;127(2):175-86

26. Dwivedi N, Chandra S, Kashyap B, Raj V, Agarwal AJCcd. Suprabasal expression of Ki-67 as a marker for the severity of oral epithelial dysplasia and oral squamous cell carcinoma. 2013;4(1):7.

27. Brosh R, Rotter VJNrc. When mutants gain new powers: news from the mutant p53 field. 2009;9(10):701.

28. Li T, Kon N, Jiang L, Tan M, Ludwig T, Zhao Y, et al. Tumor suppression in the absence of p53-mediated cell-cycle arrest, apoptosis, and senescence. 2012;149(6):1269-83.

29. Bongers V, Snow G, Van der Waal I, Braakhuis BJEJoCPBOO. Value of p53 expression in oral cancer and adjacent normal mucosa in relation to the occurrence of multiple primary carcinomas. 1995;31(6):392-5. 